\title{
Shielding assessment in two computed tomography facilities in South-South Nigeria: How safe are the personnel and general public from ionizing radiation?
}

\author{
Akintayo Daniel Omojola, M.Sc. ${ }^{(1)}$ \\ Funmilayo Ruth Omojola, B.Sc. ${ }^{(2)}$ \\ Michael Onoriode Akpochafor, Ph.D. (3) \\ Samuel Olaolu Adeneye, Ph.D. ${ }^{(3)}$ \\ From ${ }^{(1)}$ Department of Radiology, Medical Physics Unit, Federal Medical Centre Asaba, \\ Delta, Nigeria. \\ ${ }^{(2)}$ Department of Applied Zoology, Olabisi Onabanjo University, Ago-Iwoye, \\ Ogun, Nigeria. \\ (3)Department of Radiation Biology, Radiotherapy and Radiodiagnosis, \\ College of Medicine, University of Lagos, Lagos, Nigeria. \\ Address correspondence to A.D.O. (e-mail: akintayoomojola@gmail.com)
}

\section{Abstract}

Objective: The aims of this study were to estimate the instantaneous dose rate (IDR) and annual dose rate (ADR) to radiation staff and the general public within the controlled and supervised areas, respectively, to determine the shielding design goals $(\mathrm{P})$ of the $2 \mathrm{CT}$ facilities and to determine the average annual dose $\mathrm{AD})$ to radiographer/operator in the control console during CT scans.

Materials and Methods: The equipment used in this study consisted of two newly installed General Electric (GE) Revolution ACTs CT machines. Technical parameters used were a thoracic/dorsal spine scan, which was rarely done in both facilities. A calibrated Inspector USB (S.E. International, Inc.) survey meter was positioned $<50 \mathrm{~cm}$ from each barrier at various points to determine the average shielded air kerma. 
Results: The average background radiation in the 2 facilities was $0.11 \mu \mathrm{Sv} / \mathrm{hr}$. The average $\mathrm{ADR}$ to the controlled and supervised areas in $\mathrm{CT}_{1}$ was $0.563 \pm 0.25$ and $0.369 \pm 0.11 \mathrm{mSv} / \mathrm{yr}$, respectively. Also, the average ADR to the controlled and supervised areas in $\mathrm{CT}_{2}$ were $0.410 \pm 0.28$ and $0.354 \pm 0.04 \mathrm{mSv} / \mathrm{yr}$, respectively. The average shielding design goal to the controlled and supervised areas for $\mathrm{CT}_{1}$ was $0.00898 \pm 0.0041$ and $0.0059 \pm 0.0028 \mathrm{mSv} /$ Week, respectively. Similarly, the average shielding design goal for the controlled and supervised areas for $\mathrm{CT}_{2}$ was $0.0066 \pm 0.0044$ and $0.0057 \pm 0.0019 \mathrm{mSv} /$ Week respectively. The estimated average $\mathrm{AD}$ to the operator in $\mathrm{CT}_{1}$ and $\mathrm{CT}_{2}$ was 2.5 and $1.3 \mu \mathrm{Sv}$, respectively.

Conclusion: The average ADR and shielding design goals in the controlled and supervised areas from both CTs were within acceptable limits for radiation staff and the public.

Keywords: Controlled areas, Supervised area, Shielding design goal, Radiation staff, Shielding.

\section{Introduction}

The use of X-ray as a tool in diagnostic radiology have generally improved patient care and management but the harmful effects of ionizing radiation to patients and exposed staffs have raised much concern over the years[1-3]. Radiation shielding is an important aspect of radiation protection. Several recommendations have been put in place to address patient dose through the principle of "As low as reasonably achievable" (ALARA) and protocol optimization. The use of appropriate protective screens/shielding device and the principle of keeping a distance from the source have been used to address staff dose in diagnostic and interventional procedures. Similarly, access to radiation zones in a diagnostic X-ray facility has been used to restrict the general public to some places. All of these principles are well documented in the International Commission on Radiological Protection (ICRP), the National Council on Radiation Protection and Measurements (NCRP), and the International Atomic Energy Agency (IAEA) standards/recommendations, among others[4-12]. In 
order to ensure safety in diagnostic imaging, areas are usually categorized into controlled and supervised areas. A controlled area is a limited access area in which occupationally exposed radiation staff are under the supervision of an individual in charge of radiation protection or is a work area in which the annual radiation doses may exceed $3 / 10$ ths of the annual maximum permissible doses for exposed workers. This implies that access, occupancy and working conditions are controlled for radiation protection purposes. Staff in these areas are the radiologists, radiographers and radiological nurses. Supervised or uncontrolled areas are those occupied by individuals such as patients, visitors to the facility, and employees who do not work routinely with or around radiation sources. Areas adjacent to but not part of the x-ray facility are also uncontrolled areas. The controlled and supervised areas have their respective shielding design goals $(\mathrm{P})$. Shielding Design Goals $(\mathrm{P})$ are practical values, for a single X-ray source or a set of sources, that are evaluated at a reference point beyond a protective barrier[13-15].

Prior to the installation of a CT machine, it is paramount that the CT room size be adequate. Other factors that must be considered is the type of CT, and the type of shielding materials that would be used. In Nigeria today, there are more CTs in privately owned diagnostic centres compared to government hospitals. Studies have shown that most diagnostic X-ray facilities in Nigeria are not purposely built and shielding assessments were hardly done $[16,17]$.

Assessment of shielding barriers in both facilities has not be investigated; likewise, the adequacy of the use blocks plus lead as barriers have not been determined. The expectation of this study is to find out if the current shielding designs meet internationally recommended standards.

This study aimed to estimate IDR and ADR to radiation staff within the controlled areas and other persons within the supervised areas. Comparison would be made with ICRP recommended limits and it would determine if the shielding design goals (P) in both areas are within the NCRP Report 147 recommended limits. Similarly, this study would determine the average $\mathrm{AD}$ to radiographers/operators in the control console during CT scans. 


\section{Materials and methods}

This study was carried out within six weeks, following the installation of two identical CT units supplied by General Electric (GE) at two different areas in Asaba, Delta state, South-South Nigeria. The technical specifications and protocol for determining the dose rates are represented (Table 1 and 2). Both CT rooms were lead lined, with existing block walls as barriers. It is recommended by the Nigerian Nuclear Regulatory Authority (NNRA) that a CT room be adequate to attenuate scatter radiation to background values based on NCRP Report 147 document. According to NNRA regulation, it is expected that a Medical Physicist /Radiation Safety Officer do an assessment to determine if the barriers are adequate and if the shielding design goals are met. Prior to this assessment, the rooms' dimensions were determined using a measuring tape. All areas were marked and classified based on their occupancy factors. Areas like the control boots, adjacent $\mathrm{X}$-ray room, and the door leading to the CT room were classified as controlled areas, while other locations were taken as supervised areas.

Table 1. Technical specification for the CT machines.

\begin{tabular}{lll}
\cline { 2 - 3 } & \multicolumn{1}{c}{ CT $_{\mathbf{1}}$} & \multicolumn{1}{c}{$\mathrm{CT}_{\mathbf{2}}$} \\
\hline X-ray model & Revolution ACTs & Revolution ACTs \\
Model no & 5331186 & $2326492-36$ \\
Serial no & $42051 \mathrm{BG} 3$ & $60739 \mathrm{BG} 0$ \\
Tube current & $200 \mathrm{~mA}$ equivalent with ASiR & $200 \mathrm{~mA}$ equivalent with ASiR \\
Maximum power rating & $40 \mathrm{~W}$ equivalent with ASiR & $40 \mathrm{~W}$ equivalent with ASiR \\
Kv range & $80 / 100 / 120 / 140$ & $80 / 100 / 120 / 140$ \\
Scan range & $1350 \mathrm{~mm}$ (with extender) & $1350 \mathrm{~mm}$ (with extender) \\
Slice per rotation & $4 / 16^{*}$ & $4 / 16^{*}$ \\
Minimum slice thickness $(\mathrm{mm})$ & 0.625 & 0.625 \\
Date of manufacture & January 2018 & October 2019 \\
\hline
\end{tabular}

AsiR is Adaptive Statistical Iterative Reconstruction algorithm, ${ }^{*}$ the slice per rotation can be above 16-slice. 
Table 2. Average scan parameters for $C T_{1}$ and $C T_{2}$.

\begin{tabular}{|ccc}
\hline Parameters & CT $_{\mathbf{1}}$ & CT $_{\mathbf{2}}$ \\
\hline Scan type & Helical & Helical \\
\hline Tube potential & 140 & 140 \\
Tube current & $150-200 \mathrm{~mA}$ & $150-200 \mathrm{~mA}$ \\
Slice thickness & $2.5-5 \mathrm{~mm}$ & $2.5-5 \mathrm{~mm}$ \\
Tilt & 0.00 & 0.00 \\
\hline Start/End & $>250 \mathrm{~mm}$ & $>250 \mathrm{~mm}$ \\
\hline
\end{tabular}

An inspector USB survey meter was used for radiation measurements. Background measurements were made. This was to ascertain if there were any environmental factors that could influence the measurements. The Inspector USB survey meter is a health and safety instrument that is operated to detect low levels of radiation. It is designed to measure Alpha $(\alpha)$ and Beta particles $(\beta)$, Gamma rays $(\gamma)$ and X-ray radiation (ionizing radiation only). It has the capacity to work in milliroengens per hour $(\mathrm{mR} / \mathrm{hr})$ and counts per minute (CPM) or S.I units' microsievert per hour $(\mu \mathrm{Sv} / \mathrm{hr})$ and counts per second (cps) with operating range of $0.001(1 \mu \mathrm{R})$ to $100 \mathrm{mR} / \mathrm{hr}$ or 0 to $350,000 \mathrm{CPM}$ (Figure 1). Technical parameters for the worst case scenario were used. These parameters were rarely used. A Helios QA test phantom was positioned at the isocentre to produce scatter radiation in both facility (Figure 2). The survey meter was positioned $<50 \mathrm{~cm}$ away from the barrier to take measurement in all designated areas. Also, the unshielded air kerma was obtained by positioning the same meter at $<50 \mathrm{~cm}$ before the control console lead glass to estimate the barrier thickness. Three measurements were made per position and the average values were calculated. Measurements were made from a total of 20 points each in both facilities. All measurements were made by setting the survey meter to start measurement within a time frame of 60 seconds. The average time scan time was 30 seconds and the remaining 30 seconds were assumed as background values. To compensate for this error, we determined normal background radiation and deducted it from the value 
obtained during scanning. The detector unit of measurements was counts per minute (CPM) and a calibration factor $(3340 \mathrm{CPM} / \mathrm{mR} / \mathrm{hr})$ was applied to determine the dose rate in $\mathrm{mR} / \mathrm{hr}$, which was given as:

$$
m R / h r=\frac{x C P M}{3340 \frac{C P M}{m R / h r}} \quad[1]
$$

Where $\mathrm{x}$ is count recorded by the survey meter in CPM (Figure 1).

The results above in $\mathrm{mR} / \mathrm{hr}$ can then be converted to $\mu \mathrm{Sv} / \mathrm{hr}$ or $\mathrm{mSv} / \mathrm{hr}$ to estimate the IDR. Also, estimated ADR was calculated, by multiplying the IDR by 8 working hours per day and 313 days per year (excluding holidays). The AD was determined by considering 10 scans per week, with each scan taking an average of 30.59 seconds for a thoracic/dorsal spine CT. The lead equivalent thickness of the control console was determined using the transmission factor approach:

$$
B=\frac{K_{S}^{1}\left(\frac{\mu S v}{h r}\right)}{K_{S}^{2}\left(\frac{\mu S v}{h r}\right) \frac{D 1}{D 2}}
$$

Where

$\mathrm{B}$ is Secondary transmission

$\mathrm{K}_{\mathrm{S}}^{1}$ is Unshielded air kerma just before the console barrier.

$\mathrm{K}_{\mathrm{S}}^{2}$ is Shielded air kerma $30 \mathrm{~cm}$ after the console barrier.

$\mathrm{D} 1$ is Distance $(\mathrm{m})$ from source to unshielded area,

D2 is Distance (m) from source to shielded area.

The lead equivalent thicknesses $(\mathrm{mm})$ were determined from the CT transmission factor graph in NCRP 147 report. 

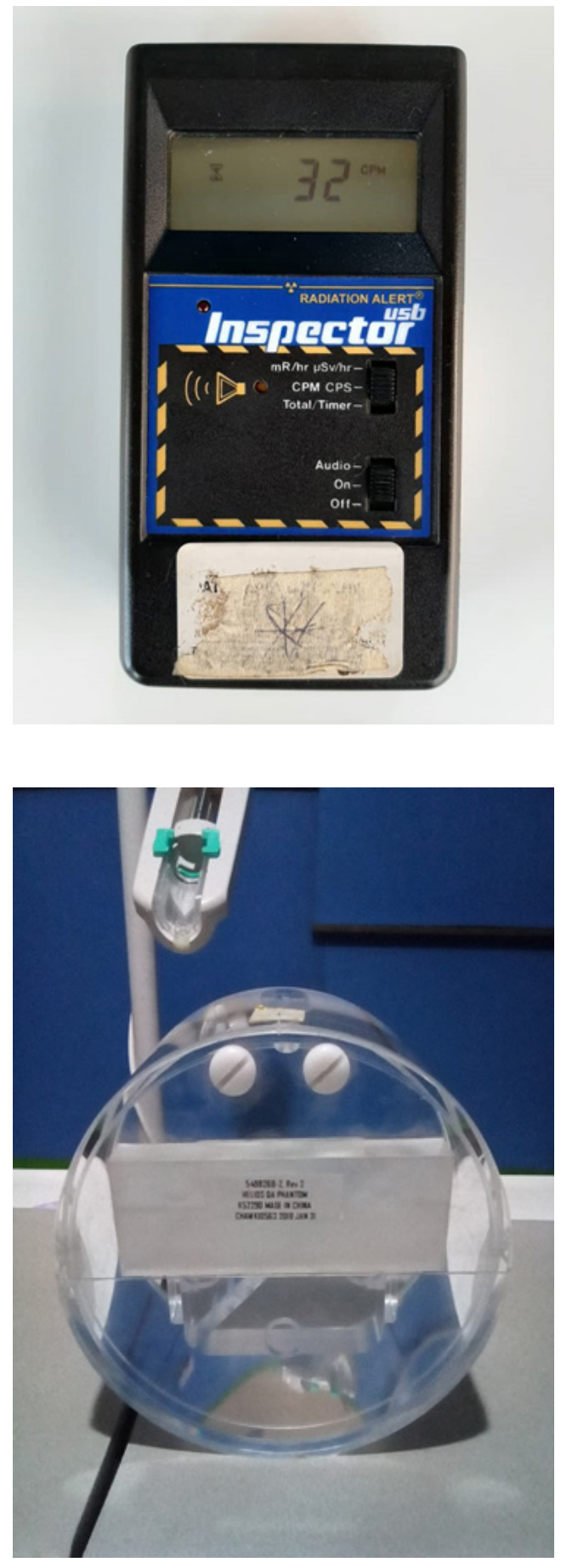

Figure 1. The Inspector USB Survey meter in counts per minute (CPM).

Figure 2. Test phantom (Helios QA Phantom). 


\section{Results}

To begin with, the average background in $\mathrm{CT}_{1}$ and $\mathrm{CT}_{2}$ was 0.11 and $0.10 \mu \mathrm{Sv} / \mathrm{hr}$, respectively. The room size for $\mathrm{CT}_{1}$ was $28.4 \mathrm{~m}^{2}$ with a height $3.0 \mathrm{~m}$. A total of 20 points located within and outside of the CT room was measured using an Inspector USB survey meter (Figure 1). The average IDR from 4 and 16 points in the controlled and supervised areas was $0.225 \pm 0.046 \mu \mathrm{Sv} / \mathrm{hr}$ and $0.148 \pm 0.102 \mu \mathrm{Sv} / \mathrm{hr}$, respectively (Table 3).

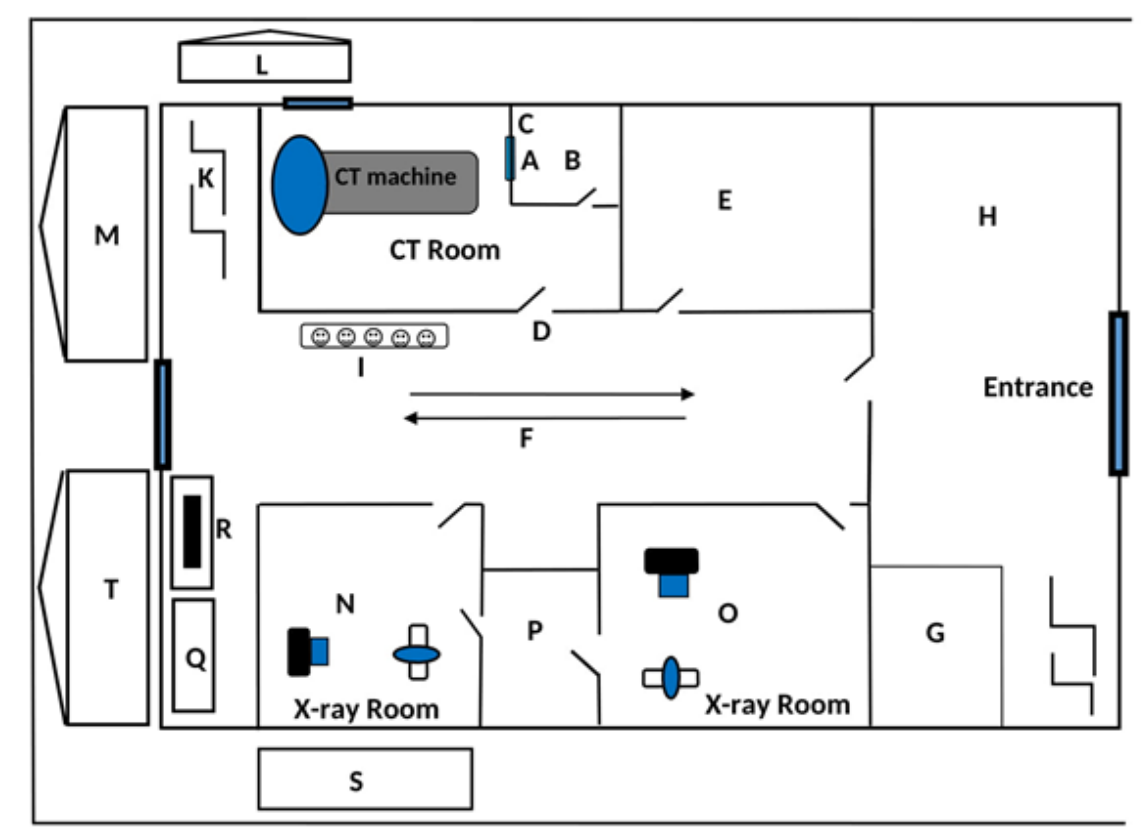

$J^{*}$ is Floor above the CT room

Figure 3. Schematic diagram of the $C T_{1}$ scanner/X-ray facilities and other areas. 
Furthermore, the ADR in CT1 from 4 points of measurements (A-D) in the controlled areas were $0.891,0.623,0.308$ and $0.428 \mathrm{mSv} / \mathrm{yr}$, respectively. Also, the ADR from 16 points in the supervised areas ranged from $0.193-0.576 \mathrm{mSv} / \mathrm{yr}$ (Table 3).

Table 3. IDR and ADR from 20 points of measurements in and around the $C T_{1}$.

\begin{tabular}{|c|c|c|c|}
\hline Point & Location & IDR $(\mu S v / h r)$ & ADR (mSv/yr) \\
\hline A & ${ }^{\star}$ Control console (lead glass) & $0.356 \pm 0.158$ & 0.891 \\
\hline B & ${ }^{\star}$ Control console [upper area] & $0.249 \pm 0.082$ & 0.623 \\
\hline $\mathrm{C}$ & ${ }^{\star}$ Control console [areas apart from lead glass] & $0.123 \pm 0.017$ & 0.308 \\
\hline $\mathrm{D}$ & ${ }^{\star}$ Door [Main entrance to CT room] & $0.171 \pm 0.093$ & 0.428 \\
\hline $\mathrm{E}$ & ${ }^{\ddagger}$ Room behind the control console [unoccupied] & $0.135 \pm 0.066$ & 0.338 \\
\hline $\mathrm{F}$ & ${ }^{\ddagger}$ Walkway & $0.156 \pm 0.037$ & 0.391 \\
\hline G & ${ }^{\ddagger}$ Receptionist desk & $0.110 \pm 0.057$ & 0.275 \\
\hline $\mathrm{H}$ & ${ }^{\ddagger}$ Patient waiting area [1] & $0.145 \pm 0.073$ & 0.363 \\
\hline I & ${ }^{\ddagger}$ Patient waiting area [2] & $0.216 \pm 0.107$ & 0.541 \\
\hline $\mathrm{J}$ & Floor above the CT room & $0.120 \pm 0.006$ & 0.300 \\
\hline $\mathrm{K}$ & ${ }^{\ddagger}$ Staircase area behind the CT room & $0.209 \pm 0.072$ & 0.523 \\
\hline $\mathrm{L}$ & ${ }^{\ddagger}$ Kitchen area & $0.182 \pm 0.091$ & 0.456 \\
\hline M & ${ }^{\ddagger}$ Residential staff area [1] & $0.153 \pm 0.073$ & 0.383 \\
\hline $\mathrm{N}$ & ${ }^{\ddagger} \mathrm{X}$-ray room 1 & $0.118 \pm 0.042$ & 0.295 \\
\hline $\mathrm{O}$ & ${ }^{\ddagger} \mathrm{X}$-ray room 2 & $0.137 \pm 0.030$ & 0.343 \\
\hline $\mathrm{P}$ & ${ }^{\ddagger}$ Film processing room & $0.179 \pm 0.082$ & 0.448 \\
\hline Q & ${ }^{\ddagger}$ Toilet area & $0.230 \pm 0.107$ & 0.576 \\
\hline $\mathrm{R}$ & ${ }^{\ddagger}$ UPS area & $0.107 \pm 0.013$ & 0.268 \\
\hline S & ${ }^{\ddagger}$ Generator area & $0.086 \pm 0.034$ & 0.215 \\
\hline $\mathrm{T}$ & ${ }^{\ddagger}$ Residential staff area [2] & $0.077 \pm 0.030$ & 0.193 \\
\hline
\end{tabular}

${ }^{*}$ controlled areas, ${ }^{\dagger}$ supervised areas, IDR is Instantaneous Dose Rate, ADR is Annual Dose Rate. 
In addition, the shielding design goals (air kerma) from 4 points were 0.0142 , $0.00996,0.00492$ and $0.00684 \mathrm{mGy} / \mathrm{wk}$, respectively in the controlled area. Also, the shielding design goals from 16 points ranged from $0.00308-0.0092 \mathrm{mGy} / \mathrm{wk}$ in the supervised area (Figure 4).
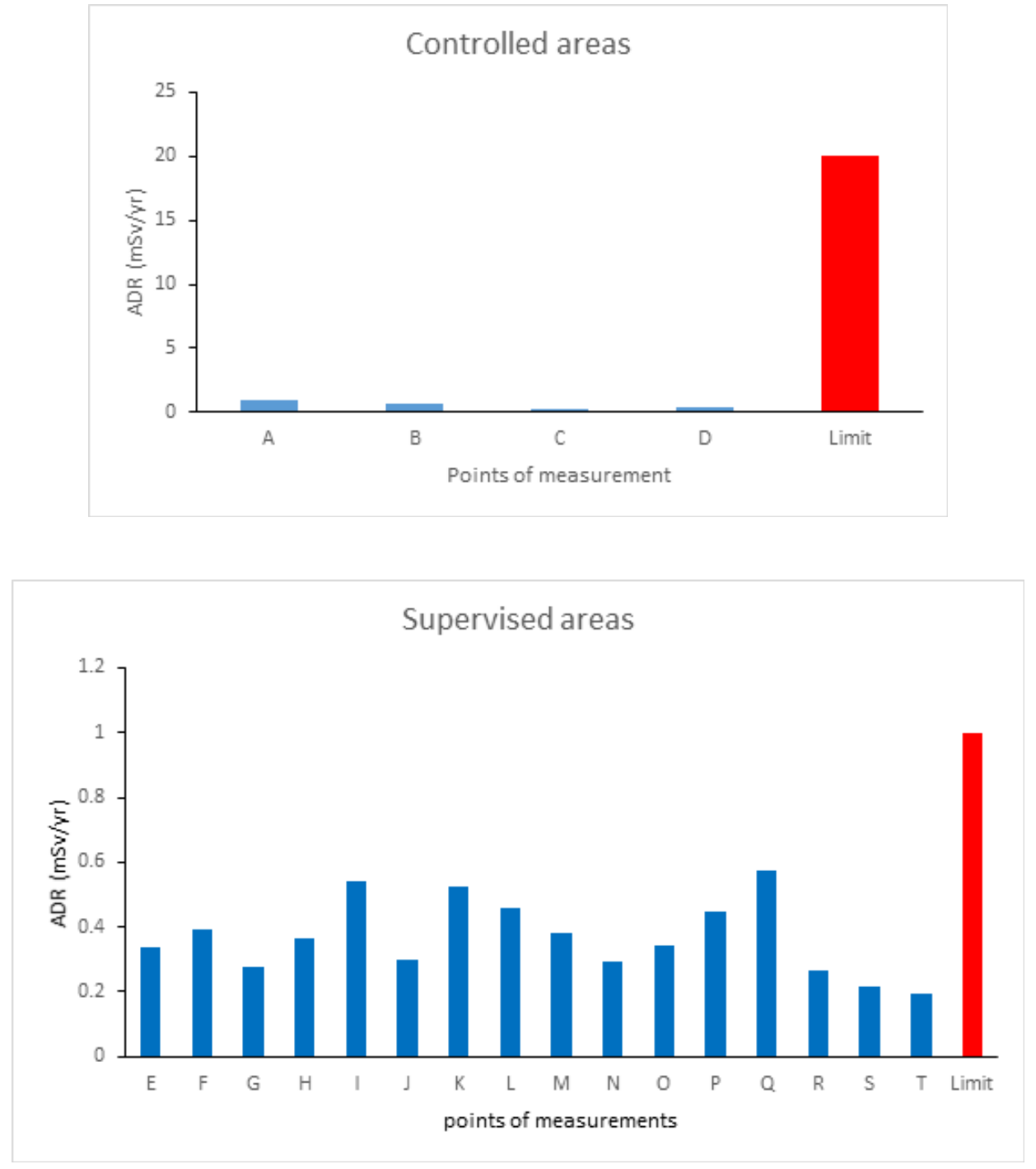

Figure 4. Comparison of ADR for controlled and supervised areas against ICRP recommended limit for $C T_{1}$. 

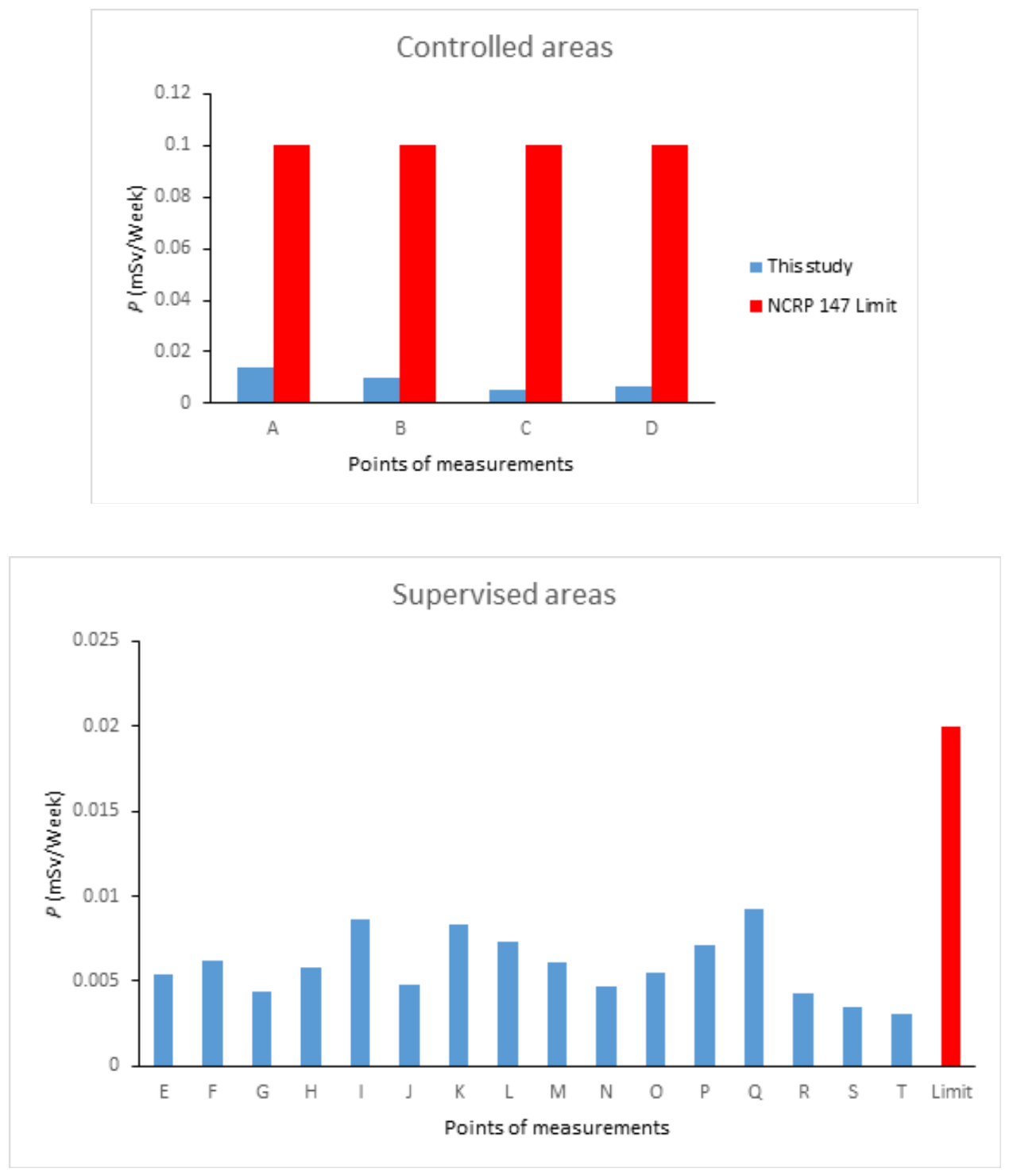

Figure 5. Comparison of shielding design goal (P) of this study with NCRP 147 recommendations for controlled and supervised areas for $C T_{1}$. 
The room size for $\mathrm{CT}_{2}$ was $25.4 \mathrm{~m}^{2}$ with a height of $2.7 \mathrm{~m}$. A total of 20 points located within and outside the CT room were measured using the same survey meter. The average IDR from 6 and 14 points in the controlled and supervised areas was $0.164 \pm 0.111 \mu \mathrm{Sv} / \mathrm{hr}$ and $0.141 \pm 0.047 \mu \mathrm{Sv} / \mathrm{hr}$ (Table 4).

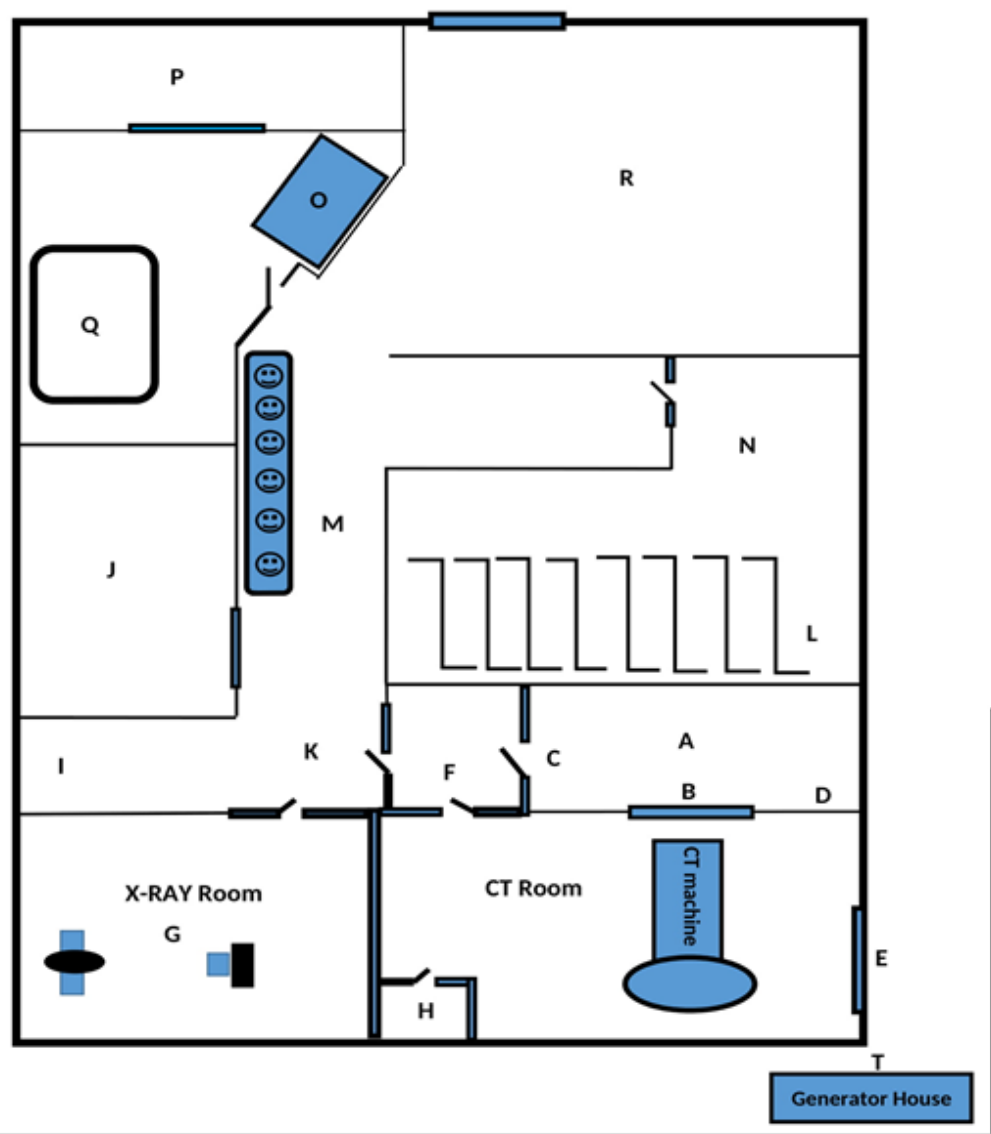

$S$ is Occupied area above the CT \& X-ray

Figure 6. Schematic diagram of the $C T_{2}$ scanner/X-ray facilities and other areas. 
Table 4. IDR and ADR from 20 points of measurements in and around the $C T_{2}$.

\begin{tabular}{|c|c|c|c|}
\hline Point & Location & IDR $(\mu \mathrm{Sv} / \mathrm{hr})$ & $\operatorname{ADR}(\mathrm{mSv} / \mathrm{yr})$ \\
\hline $\mathrm{A}$ & ${ }^{\star}$ Control console & $0.100 \pm 0.066$ & 0.250 \\
\hline B & ${ }^{\star}$ Control console [lead glass] & $0.225 \pm 0.142$ & 0.563 \\
\hline $\mathrm{C}$ & ${ }^{\star}$ Control console [ right wall] & $0.089 \pm 0.035$ & 0.223 \\
\hline $\mathrm{D}$ & ${ }^{\star}$ Control console [left wall] & $0.098 \pm 0.009$ & 0.245 \\
\hline $\mathrm{E}$ & ${ }^{\ddagger}$ Exit door to generator area $[1]$ & $0.096 \pm 0.007$ & 0.240 \\
\hline $\mathrm{F}$ & ${ }^{\star}$ Door leading to CT Room & $0.365 \pm 0.171$ & 0.914 \\
\hline G & ${ }^{\star} \mathrm{X}$-ray Room & $0.105 \pm 0.054$ & 0.263 \\
\hline $\mathrm{H}$ & ${ }^{\ddagger}$ Online UPS room (unoccupied area) & $0.210 \pm 0.097$ & 0.525 \\
\hline I & ${ }^{\ddagger}$ Exit door [2] & $0.113 \pm 0.035$ & 0.283 \\
\hline $\mathrm{J}$ & ${ }^{\ddagger}$ Director’s office & $0.099 \pm 0.022$ & 0.247 \\
\hline $\mathrm{K}$ & ${ }^{\ddagger}$ Main door leading to CT Suit & $0.269 \pm 0.120$ & 0.674 \\
\hline $\mathrm{L}$ & †Walkway leading upstairs & $0.120 \pm 0.068$ & 0.300 \\
\hline M & ${ }^{\ddagger}$ Walkway leading to radiation areas & $0.143 \pm 0.011$ & 0.358 \\
\hline $\mathrm{N}$ & ‡Toilet $[1]$ & $0.153 \pm 0.062$ & 0.383 \\
\hline $\mathrm{O}$ & ${ }^{\ddagger}$ Typing desk & $0.105 \pm 0.013$ & 0.263 \\
\hline $\mathrm{P}$ & ${ }^{\ddagger}$ Laboratory & $0.135 \pm 0.045$ & 0.338 \\
\hline Q & ${ }^{\ddagger}$ Receptionist desk & $0.141 \pm 0.015$ & 0.353 \\
\hline $\mathrm{R}$ & ${ }^{\ddagger}$ Patient waiting area & $0.147 \pm 0.070$ & 0.368 \\
\hline S & ${ }^{\ddagger}$ Occupied area above the CT \& X-Ray room & $0.113 \pm 0.034$ & 0.283 \\
\hline $\mathrm{T}$ & ${ }^{\ddagger}$ Generator house & $0.135 \pm 0.080$ & 0.338 \\
\hline
\end{tabular}

${ }^{*}$ controlled areas, ${ }^{\ddagger}$ supervised areas, IDR is Instantaneous Dose Rate, ADR is Annual Dose Rate.

Likewise, the ADR from 6 points of measurements in the controlled areas was $0.250,0.563,0.223,0.245,0.914$ and $0.263 \mathrm{mSv} / \mathrm{yr}$, respectively. Also, the ADR from 14 points of measurements in supervised areas ranged from 0.24-0.674 mSv/yr (Figure 7). 
THE ASEAN JOURNAL OF RADIOLOGY
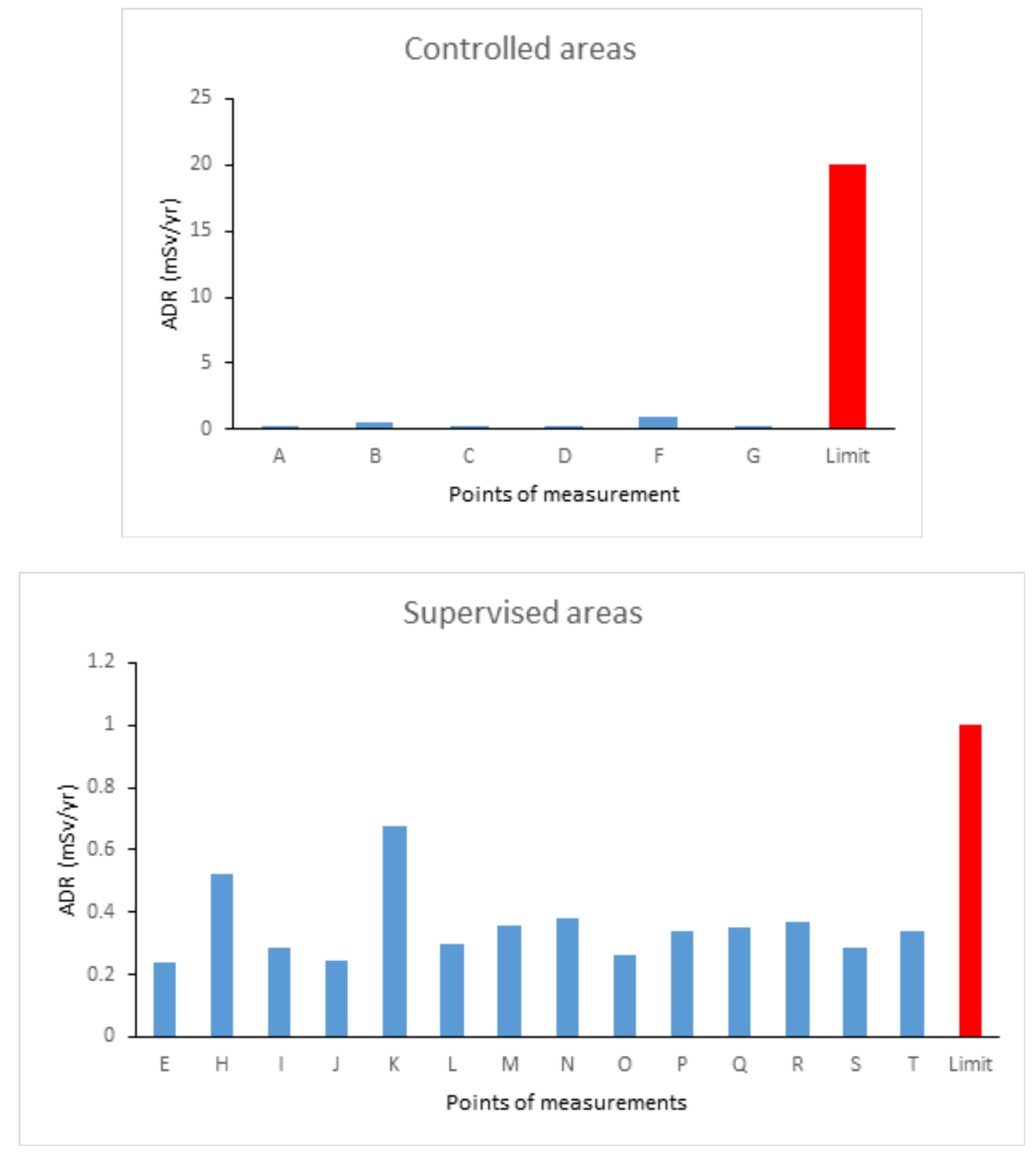

Figure 7. Comparison of ADR for controlled and supervised areas against the ICRP recommended limit for $\mathrm{CT}_{2}$. 
Again, the shielding design goals (air kerma) from 6 points were 0.004, 0.009, $0.00356,0.00392,0.00146$ and $0.0042 \mathrm{mGy} / \mathrm{wk}$, respectively. The shielding design goals from 14 points ranged from $0.00108-0.0084 \mathrm{mGy} / \mathrm{wk}$ (Figure 8).
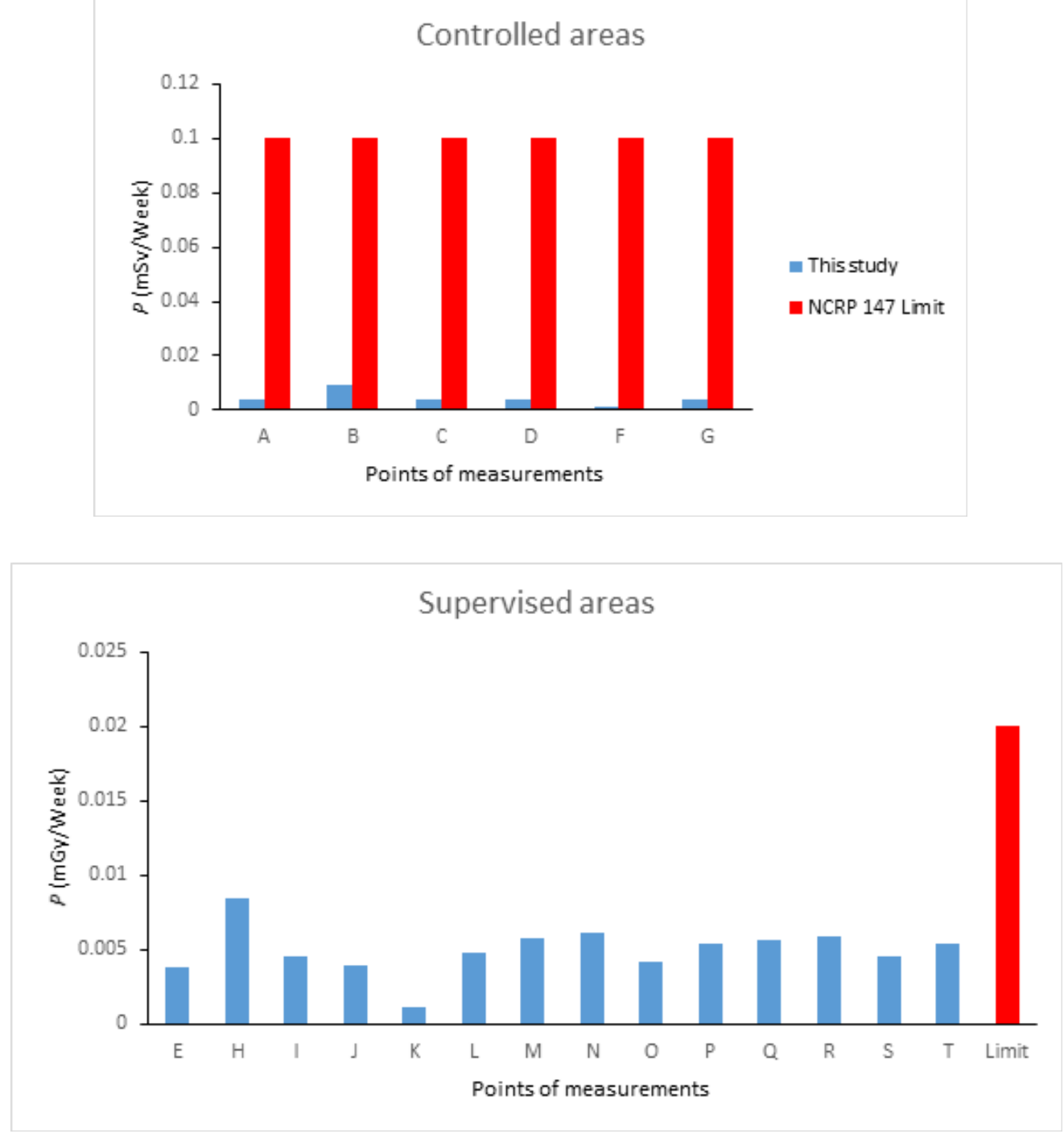

Figure 8. Comparison of shielding design goal (P) of this study with NCRP 147 recommendations for controlled and supervised areas for $\mathrm{CT}_{2}$. 
Finally, the barrier thickness in $\mathrm{CT}_{1}$ and $\mathrm{CT}_{2}$ was 2.1 and $2.6 \mathrm{~mm}$, respectively and $\mathrm{AD}$ for the radiographer/operator in $\mathrm{CT}_{1}$ and $\mathrm{CT}_{2}$ was $2.5 \mu \mathrm{Sv}$ and $1.3 \mu \mathrm{Sv}$, which amounted to an overall average dose of $2 \mu \mathrm{Sv}$ (Table 5).

Table 5. Estimated annual dose to the operator in the control console.

\begin{tabular}{|lccccc} 
CT & Location & $\begin{array}{c}\text { X-ray source } \\
\text { to console }(\mathbf{m})\end{array}$ & $\begin{array}{c}\text { Lead equivalent } \\
\text { thickness }(\mathbf{m m})\end{array}$ & IDR $(\mu \mathrm{Sv} / \mathrm{hr})$ & AD $(\boldsymbol{\mu S v})$ \\
\hline $\mathrm{CT}_{1}$ & Control console & 3.24 & 2.1 & 0.243 & 2.46 \\
$\mathrm{CT}_{2}$ & Control console & 3.25 & 2.6 & 0.128 & 1.29
\end{tabular}

$A D$ is Annual dose.

\section{Discussion}

A study to estimate the IDR, ADR, shielding design goals $(\mathrm{P})$ and $\mathrm{AD}$, within and outside two similar CT machines has been carried out. The ADR with both CTs to the controlled areas were $<20 \mathrm{mSv} / \mathrm{yr}$ and the shielding design goals was $<0.1 \mathrm{mSv} /$ wk recommended by NCRP Report 147. Similarly, the ADR with both CTs to the supervised areas were $<1 \mathrm{mSv} / \mathrm{yr}$ recommended by ICRP and the shielding design goals were $<0.02 \mathrm{mSv} /$ wk recommended by NCRP Report 147. The estimated ADs to the control console where the radiographer/operator occupy during every CT scan were $<20 \mathrm{mSv}$ ICRP limit.

Deductions from this study shows that $43 \%$ and $74 \%$ of the measured IDR with $\mathrm{CT}_{1}$ and $\mathrm{CT}_{2}$, at the controlled areas were close to background. Similarly, $67 \%$ and $78 \%$ of the IDR with $\mathrm{CT}_{1}$ and $\mathrm{CT}_{2}$, at the supervised areas were close to the background. These results indicate the effectiveness of the walls and the lead materials used for shielding. Over $70 \%$ of the IDR at the supervised areas was closer to background values; this was because of the distances and barriers that would be encountered before reaching the CT room. From this study, $\mathrm{CT}_{2}$ had 
thicker barriers compared to $\mathrm{CT}_{1}$. The background values from this study were similar to the value obtained by Owusu-Banhene et al in Ghana, who conducted a research on dose rate assessment in diagnostic radiology and Joseph et al in a similar study carried out in Nigeria[18, 19].

Furthermore, the shielding design goals in this study were based on NCRP Report 147 document, which was updated from an initial document (NCRP 49). The standards obtained in this document is relevant for all medical imaging facilities, including CTs. In the light of these, the shielding design goal in our study in the controlled areas from both CTs were higher ( 0.00898 and $0.0066 \mathrm{mSv} / \mathrm{wk})$, compared to a study by Nkubli et al, who used a survey meter similar to ours to determine the shielding design goals from $4 \mathrm{X}$-ray facilities. His design goals ranged from 0.00152-0.00496 mSv/week. The differences observed were expected because CT systems produce larger scatter radiation compared to conventional $\mathrm{X}$-ray systems[20]. In contrast to this, there was variation in the shielding design goals between our study and a study by Okon et al, who used thermoluminescent dosimeters (TLDs) in Kaduna State Nigeria, with the conventional X-ray system. The shielding design goal from our study was lower compared to Okon's study. Detector responses may have affected the dose rates observed[21].

This study's average IDR for $\mathrm{CT}_{1}$ and $\mathrm{CT}_{2}$ in the controlled areas (8.89 and 6.6 $\mu \mathrm{Sv} /$ week) was lower compared to a study by Nkansah et al, where the average dose rate in the controlled areas was $18 \mu \mathrm{Sv} /$ week. The aforementioned differences in the controlled areas may be due to the protocol used, the distance of the CT from the console, the position of the detector, the type of the detector used and barrier thickness. Similarly, this study showed an average IDR from both CTs in the supervised areas (5.9 and $5.7 \mu \mathrm{Sv} /$ week) was slightly higher than Nkansah's study which was $3.4 \mu \mathrm{Sv} /$ week[22]. The average IDR in the control console in this study was very low $(0.2 \mu \mathrm{Sv} / \mathrm{hr})$ compared to a study by Mohammed et al $(7.05 \mu \mathrm{Sv} / \mathrm{hr})$, who also investigated ambient dose rate in the control room in a CT study. Differences observed may be due to factors such as the distance of the CT to the control room, the CT protocol and barrier thickness[23]. 
Estimation of the control console dose near the lead glass for $\mathrm{CT}_{1}(3.6 \mu \mathrm{Sv})$ and $\mathrm{CT}_{2}(2.3 \mu \mathrm{Sv})$ was the highest compared to other areas in the CT room. Dose to personnel at the extreme side, in the control console for $\mathrm{CT}_{1}(1.2 \mu \mathrm{Sv})$ and $\mathrm{CT}_{2}$ $(0.9 \mu \mathrm{Sv})$ were the least. This claim proved to be accurate when compared to a study by palm \& Nelson, who investigated staff dose in the control console. Their findings show that a dose to areas at the side in the console of the CT had the least dose $(0.42 \mu \mathrm{Sv})$; however, the dose to personnel facing the gantry, through the lead glass was quite higher $(96 \mu \mathrm{Sv})$ than this study[24].

Furthermore, the ADR in the controlled areas between both CTs in this study were close. We observed that the room dimension for $\mathrm{CT}_{1}$ was larger compared to $\mathrm{CT}_{2}$, but the shielded air kerma from $\mathrm{CT}_{2}$ attenuated more of the scatter radiation. Although both CT room dimensions were below the recommended standards of $45 \mathrm{~m}^{2}$ as required by the International Health Facility Guideline (IHFG); in addition, both CT control console rooms were below $14 \mathrm{~m}^{2}$ proposed by the iHFG document [25]. In another comparison, the room dimensions in this study met the Uganda Atomic Energy Council (UAEC) guideline, which recommended a total room area of $\geq 25 \mathrm{~m}^{2}$ (with at least $4 \mathrm{~m}$ for each length). The control cubicle for both CTs were approximately $4 \mathrm{~m}^{2}$ which was below UAEC required area $\left(5 \mathrm{~m}^{2}\right)$. The control cubicle heights from this study were above the recommended height by UAEC, which was $2.0 \mathrm{~m}[26]$.

\section{Conclusion}

This study has verified the safety of personnel and the public in and around the CT room during scanning. The estimated ADR from both CTs in the controlled and supervised areas were within an acceptable limit. Similarly, the shielding design goals were within the recommended standards. From this study, the staff working in the control console were safe and the general public who occasionally stay in the patient waiting area were safe. Occasionally, radiation workplace monitoring should be carried out to ensure the general safety of everyone within the facility. 


\section{Limitations}

1. At longer distances from the control booth to other areas where measurements were taken, it was difficult to communicate with the radiographer when to start exposure and to ascertain when exposure was over.

2. The actual count by the survey meter was challenging to note due to the influence of background count after exposure.

\section{Recommendations}

1. Shielding should be done according to the room size, the type of CT system, protective materials and workload. This will ensure that the shielding design goals are properly met.

2. Sensitive survey meter should be used for shielding assessment.

3. Adjoining wall areas should be considered while taken measurements. 


\section{References}

1. Power SP, Moloney F, Twomey M, James K, O'Connor OJ, Maher MM. Computed tomography and patient risk: facts, perceptions and uncertainties. World J Radiol 2016;8:902-15. doi:10.4329/wjr.v8.i12.902.

2. European Society of Radiology 2009. The future role of radiology in healthcare. Insights Imaging 2010;1:211. doi: 10.1007/s13244-009-0007-x.

3. European Society of Radiology (ESR); European Federation of Radiographer Societies (EFRS). Patient safety in medical imaging: a joint paper of the European Society of Radiology (ESR) and the European Federation of Radiographer Societies (EFRS). Insights Imaging 2019; 10:45. doi: 10.1186/ s13244-019-0721-y.

4. International Atomic Energy Agency (IAEA). Radiation protection and safety of radiation sources: international basic safety standards. General safety requirements Part 3. no. GSR Part 3. Vienna (Austria): IAEA Publications; 2014.

5. International Atomic Energy Agency (IAEA). Occupational radiation protection: general safety guide. no. GSG-7. Vienna (Austria): IAEA Publications; 2018.

6. Radiological protection and safety in medicine. a report of the International Commission on Radiological Protection. Ann ICRP 1996;26(2):1-47.

7. General principles for the radiation protection of workers. Ann ICRP 1997;27(1):1-60. doi: 10.1016/s0146-6453(97)88275-9.

8. López PO, Dauer LT, Loose R, Martin CJ, Miller DL, Vañó E, et al. ICRP Publication 139: Occupational Radiological Protection in Interventional Procedures. Ann ICRP 2018;47(2):1-118. doi: 10.1177/0146645317750356. 
9. Radiological Protection Institute of Ireland (RPII). The design of diagnostic medical facilities where ionising radiation is used. a code of practice issued by the Radiological Protection Institute of Ireland. Dublin (Ireland): RPII Publication; 2009.

10. Madsen MT, Anderson JA, Halama JR, Kleck J, Simpkin DJ, Votaw JR, et al. AAPM Task Group 108: PET and PET/CT shielding requirements. Med Phys 2006;33:4-15. doi: 10.1118/1.2135911.

11. National Council on Radiation Protection and Measurements (NCRP). NCRP report no. 49: structural shielding design and evaluation for medical use of $\mathrm{X}$-rays and gamma rays of energies up to $10 \mathrm{MeV}$. Bethesda (MD): NCRP; 1976.

12. International Electrotechnical Commission (IEC). Medical electrical equipment Part 1-3: General requirements for basic safety and essential performance. Collateral standard: radiation protection in diagnostic X-ray equipment. IEC 60601-1-3:2008. Geneva (Switzerland): IEC; 2008.

13. Sutton DG, Williams JR. Radiation shielding for diagnostic X-rays: report of a joint BIR/IPEM working party. London: British Institute of Radiology; 2000.

14. Dixon RL, Simpkin DJ. Primary shielding barriers for diagnostic x-ray facilities: a new model. Health Phys 1998;74:181-9. doi: 10.1097/00004032199802000-00005.

15. National Council on Radiation Protection (NCRP). NCRP report no. 147: structural shielding design for medical X-ray imaging facilities. Bethesda (MD): NCRP; 2004.

16. Adejoh T, Nwogu BU, Anene NC, Onwujekwe CE, Imo SA, Okolo CJ, et al. Computed tomography scanner distribution and downtimes in southeast Nigeria. J Assoc Rad Niger 2017; 31: 8-15. 
17. Akpochafor $\mathrm{MO}$, Omojola $\mathrm{AD}$, Adeneye SO, Ekpo V, Adedewe NA, Adedokun AR et al. Computed tomography dose reference level for noncontrast and contrast examination in $13 \mathrm{CT}$ facilities in South-West Nigeria. PJR 2018;28:285-93.

18. Owusu-Banahene J, Darko EO, Charles DF, Maruf A, Hanan I, Amoako G. Scatter radiation dose assessment in the Radiology Department of Cape Coast Teaching Hospital-Ghana. Open J Radiol 2018;8:299-3. doi: 10.4236/ ojrad.2018.84033.

19. Joseph DS, Ibeanu IG, Zakari YI, Joseph DZ. Radiographic room design and layout for radiation protection in some radio-diagnostic facilities in Katsina State, Nigeria. J Assoc Rad Niger 2017;31:16-23.

20. Nkubli FB, Nzotta CC, Nwobi NI, Moi SA, Adejoh T, Luntsi G, et al. A survey of structural design of diagnostic $\mathrm{x}$-ray imaging facilities and compliance to shielding design goals in a limited resource setting. J Glob Radiol 2017;3(1): Article 6. doi: 10.7191/jgr.2017.1041.

21. Okon EE. X-ray shielding barrier estimation: a case study of radiology department, Ahmadu Bello University Teaching Hospital, Shika - Zaria [dissertation]. Zaria (Nigeria): Department Of Physics, Faculty of Science, Ahmadu Bello University; 2007.

22. Nkansah A, Schandorf C, Boadu M, Fletcher JJ. Assessment of the integrity of structural shielding of four computed tomography facilities in the greater Accra region of Ghana. Radiat Prot Dosimetry 2013;155:423-31. doi: 10.1093/ $\mathrm{rpd} / \mathrm{nct} 021$.

23. Mohammed SAH. Ambient dose measurement in some CT department in Khartoum State [dissertation]. Khartoum (Sudan): Atomic Energy Council, Sudan Academy of Science; 2012. 
24. Palm F, Nelson F. The importance of medical staff placement in CT examination rooms: a study of the scattered radiation doses in CT examination rooms in Da Nang, Vietnam [dissertation]. Da Nang (Vietnam): School of Health and Welfare, Jonkoping University; 2017.

25. International Health Facility Guidelines (IHFG). Part B Health facility briefing and design: 160 medical imaging unit-general. Version 5. IHFG; 2016.

26. Uganda Atomic Energy Council (UAEC). Guidance on the designs and layout of medical radiology facilities Vol. 1, 2017. Uganda: UAEC; 2017. 